\section{Máquinas de vigiar}

\author{
Arlindo Machado
}

Nossa sociedade, como já observou Michel Foucault (1988, p. 190), é menos a dos espetáculos do que a da vigilância. Encontro-me num aeroporto qualquer, em qualquer parte do globo, esperando meu vôo a qualquer lugar. Coloco minha bagagem numa esteira rolante; imediatamente ela é bombardeada por um feixe de raios $\mathrm{x}$, que vasculha $\mathrm{o}$ seu conteúdo, em busca de substâncias ou instrumentos ilegais. Eu próprio devo me encaminhar até uma simulação de porta ou coisa parecida, onde outro dispositivo examina meu corpo e o interior de minhas roupas. Não tendo sido detectado nada suspeito, recebo do olho mecânico o go-ahead que me permite retomar a bagagem e prosseguir minha jornada em direção à sala de espera. Sento-me numa poltrona e, enquanto observo o movimento, noto que há uma câmera, discretamente colocada num canto qualquer da sala, apontada para a minha direção, vasculhando todas as minhas ações. Aliás, não há so uma; são várias, espalhadas estrategicamente por todo o saguão, de modo a não deixar um único espaço livre do escrutínio desse olhar anônimo e onividente. Então me dou conta de que todas essas câmeras já estavam me seguindo desde que desci do táxi à entrada do aeroporto, acompanhando-me ao bar quando pedi um café e quando parei na banca para comprar um jornal.

Como os demais passageiros na sala de espera, coloco uma ficha na ranhura de um dos braços da poltrona e imediatamente se acende à minha frente a tela de um pequeno receptor de TV de cinco polegadas, que me permite matar o tempo assistindo à programação local. Minha atenção, entretanto, dispersa-se e logo estou olhando para outras telas, enfileiradas em vários pontos do aeroporto: os monitores dos sistemas de vigilância, que me dão as imagens assépticas do próprio aeroporto, de seus outros salões, de seu exterior e de seus campos de pouso e decolagem. Dou-me conta de uma muzak repousante que já estava coçando meus ouvidos desde que entrei e que serve de fundo à voz monótona da locutora de avisos. "O aeroporto pode ser qualquer um. O La Guardia de Nova York, o Heathrow de Londres ou o Orly de Paris, pouco importa. Aparentemente neutros em sua placidez, os aeroportos disssimulam seu olhar atento e escrutinador sob a aparência de telas impessoais e simples estruturas arquitetônicas. (...) Os aeroportos modernos se tornaram a representação mais poderosa do novo ambiente que habitamos: um espaço de múltiplas telas, de dispositivos eletrônicos invisíveis e de um ruído incessante que ouvimos ao longe. Vamos levar ainda algum tempo para compreender a fundo o impacto em nossos sentidos e em nosso pensamento dessa nova paisagem cultural, cuja relação primeira se dá entre nós e a ubiqüidade da tela" (Brooks, 1987, p. 66).

Os sistemas eletrônicos de vigilância multiplicam-se em progressão geométrica por toda parte. Não apenas os aeroportos ou estações de trem e metrô, mas agora até mesmo as estradas, os túneis, os supermercados, os grandes magazines, os bancos, as fábricas e, no limite, escolas e instituições psiquiátricas, estão submetidos aos olhares técnicos e impessoais das câmeras de observação. Só na cidade de Hamburgo, segundo Kramer e

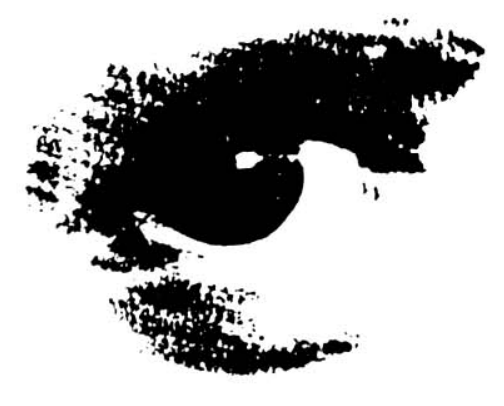

ARLINDO MACHADOÉo professor-responsável pelo Programa de Comunicação e Semiótica da PUC-SP $\theta$ autor de $A$ ilusáo especular $\mathrm{e} A$ arte do video (ambos editados pela Brasiliense). 
Klier (1987, p. 29), hâ três mil câmeras movidas por controle remoto e espalhadas por toda a zona urbana, para monitoração do sistema de tráfego. Essas câmeras estão colocadas nos lugares mais estratégicos, ocupando os ângulos mais privilegiados de visão e distribufdas no espaço de modo a não deixàr um único ponto livre do voyeurismo automático. Locais ocultos ou de configuração acidentada são refletidos para a câmera através de espelhos convexos colocados na paisagem. Na sala de controle do departamento municipal de trânsito, pode-se dar um close-up sobre qualquer transeunte que circula pelas calçadas, segui-lo secretamente até o seu destino, "cortando" de uma câmera para outra, penetrar em sua intimidade e desvendar os seus segredos.

As câmeras de vigilância se distribuem como uma rede sobre a paisagem social, ocupando todos os espaços e os submetendo ao seu poder de invasão branca, à sua penetração invisf́vel e indolor. A elas se acrescentam ainda outros dispositivos de vigilância mais localizados, como os grampeamentos de telefones e os microfones unidirecionais poderosos, capazes de captar um diálogo em voz baixa a longa distância. Depois de Watergate, não pode restar dúvidas de que as esferas do público e do privado se interpenetram cada vez mais. E em escala mais planetária, os satélites de observação e espionagem estão em condições de obter informações visuais ou acústicas de uma vasta região do globo, a ponto de poderem detectar, a duzentos quilômetros de altura, uma batida de coração ou a posição de uma agulha. Quando estourou, em 1978, o escândalo em torno dos satélites-câmeras norte-americanos Big Bird, que durante cinco anos espionaram áreas militares soviéticas, os técnicos da CIA declararam que esses engenhos eram capazes de distinguir do espaço pessoas em trajes civis e militares, a marca de um automovel e até mesmo a sua chapa (Glatzer, 1983, p. 197).

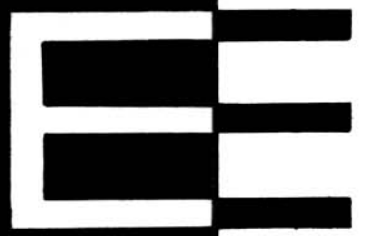

m 1983, o artista tcheco radicado em Berlim, Michel Klier, monitorando circuitos de vigilância e outros dispositivos de coerção policial, compós o poema videográfico Der Riese ( $O$ gigante), uma das peças-chaves da arte de nosso tempo, além de uma visão perturbadora do Estado policial moderno. A idéia básica desse vídeo é construir, através do acesso às salas de controle de um grande número de sistemas de vigilância espalhados por toda a Alemanha, uma colagem de cenas aleatórias obtidas por olhos mecânicos espiōes, de modo a configurar, segundo palavras do próprio realizador (Kramer e Klier, 1987, p. 29), “o momento em que o ordinário e o banal do funcionamento desses sistemas transfigura-se em imagens assombrosas de um pesadelo". Registros do dispositivo de controle do trânsito de Hamburgo, do sistema de vigilância de uma empresa de carros blindados para transporte de numerário em Frankfurt, ou de uma loja de departamentos em Berlim, ou ainda de um peep show na mesma localidade, além do aparato de segurança de uma parada militar no lado oriental da cidade, tudo isso é alinhavado com outras imagens, mais emblemáticas ou de função coercitiva menos evidente, como aquelas sintetizadas numa máquina de retrato falado da polícia de Dusseldorf, um simulador de pilotagem de tanque de guerra em Ulm, ou obtidas de uma câmera oculta numa sessão de psiquiatria legista e até mesmo de dispositivos de penetração em nosso mundo interior, como os gráficos de eletroencefalograma. O objetivo implícito é traçar um mapa do que poderia ser a reencarnação moderna de um Panoptico dissimulado e quase invisível, que se estende por todas as dimensões de nossa vida como uma teia esgarçada, porém implacável.

\section{O PANÓPTICO UNIVERSAL}

O dispositivo do Panóptico já E bem conhecido. Formulado pela primeira vez pelo jurista britânico Jeremy Bentham, ele era originalmente um projeto de prisão modelar, em que os prisioneiros ficariam enclausurados em celas individuais, dispostas em círculo ao redor de uma torre central, onde estaria colocado estrategicamente o encarregado da vigilância. Cada cela seria dotada de duas janelas, uma que daria para o exterior e através da qual a luz penetraria no compartimento, outra que daria para o interior do ć́rculo e através da qual a silhueta do detento se projetaria para fora, para os olhos da sentinela da torre central. Assim, graças ao efeito da contraluz, todos os prisioneiros resultariam perfeitamente visf́veis àquele que os vigiassem. Mas a recíproca não era verdadeira: do interior de sua cela, cada detento só poderia constatar a onipresença constrangedora da torre central, mas não perceberia o vigia, protegido que este estaria por persianas e um sistema de biombos destinado a impedir a visibilidade do interior da sala de controle. Dessa forma, os detentos poderiam ser vistos pelo vigia, mas não poderiam 
vê-lo em contrapartida, de modo que a sua presença ou ausência seria sempre inverificável. Cumprir-se-ia assim o efeito mais importante do Panóptico: fazer com que os detentos, "por uma simples idéia de arquitetura" (Bentham, 1829, p. 248), se sentissem vigiados, mesmo quando não houvesse vigia algum na torre central e mesmo quando eles não estivessem sendo diretamente observados. Em outras palavras, o poder não teria mais necessidade de se impor efetivamente, a atualidade de seu exerć́cio se tornaria mesmo inútil; o mais importante era que o detento estivesse imbúdo pela idéia de uma permanente visibilidade e que fosse ele proprio, por efeito de um simples dispositivo arquitetônico, o portador de uma relação de poder.

O corolário inevitável de todo dispositivo panóptico é que ele desindividualiza o poder, livra-o do arbítrio do inspetor, do xerife, do chefe, transformando-o numa máquina anônima, num engenho de tecnologia política de que o sistema arquitetônico é o diagrama. "Quem está submetido a um campo de visibilidade, e sabe disso, retoma por sua conta as limitações do poder; fá-las funcionar espontaneamente sobre si mesmo; inscreve em si a relação de poder na qual ele desempenha simultaneamente os dois papéis; torna-se o princípio de sua própria sujeição" (Foucault, 1988, p. 179). Os próprios vigias tornam-se eles tambem vigiados. Mas vigiados por quem? Pelo olho do público, que pode ser o olho de qualquer um. O Panóptico $E$, antes de tudo, uma escola de virtudes, onde personagens odiosos encenam diariamente o drama da punição. Como tal, ele deve ser aberto à visitação pública, deve ser um local de instrução, um teatro educativo para onde os pais levam em passeio os seus filhos, considerados criminosos potenciais. Essa circulação intensa e constante de pessoas ("por lá passarão curiosos, transeuntes, parentes dos prisioneiros, amigos dos inspetores e outros oficiais da prisão, cada um deles animado por um motivo diferente" - Bentham, 1829, p. 249) faz aumentar para o prisioneiro o risco de ser surpreendido, ampliando portanto a eficácia do dispositivo e submetendo ainda o arbítrio do vigia ao controle público. A eficácia do Panóptico reside, portanto, na despersonalização do poder, na sua transformação em pura figura geométrica, uma arquitetura exemplar de que todos participam em alguma instância.

$\mathrm{O}$ que são os modernos sistemas de vigilância senão a atualização e a universalização do Panóptico? Bentham já havia profetizado, a seu tempo, que o seu modelo "racio-

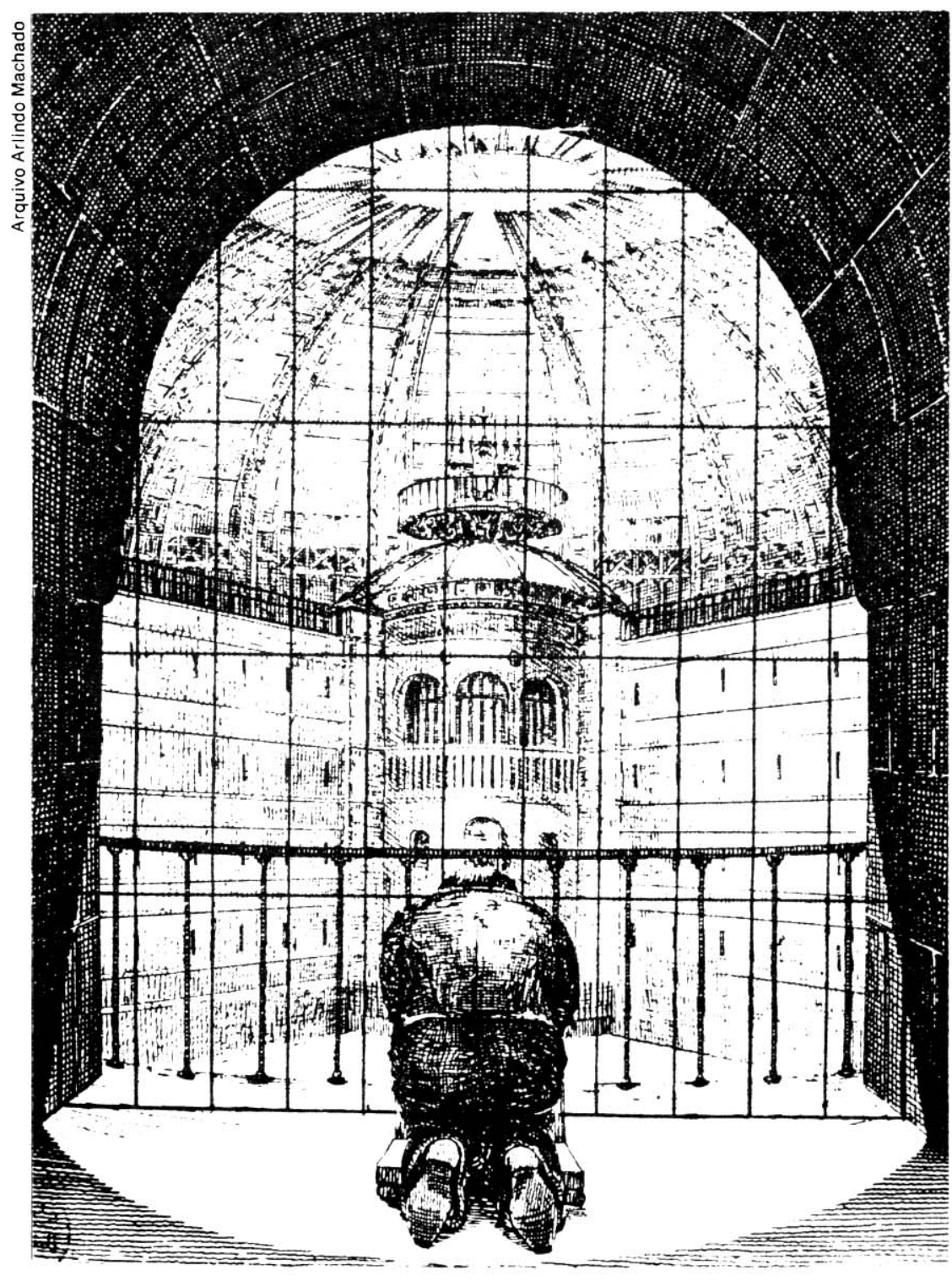
nal" de prisão poderia ser generalizado para qualquer instituição social baseada nos princípios do controle e da produtividade: fábricas, hospitais, asilos, escolas e assim por diante. Esse modelo permitiria reformar a moral dos homens, difundir a instrução, incrementar a produtividade industrial, aumentar a eficiência de todos os ambientes de trabalho, inibindo, em contrapartida, a desobediência às leis, a improdutividade e a subversão da ordem. Em 1797, tendo o Parlamento inglês adiado a decisão de construir prisões panópticas, o famoso jurista se põe a trabalhar numa adaptação de sua máquina polivalente para alojamento de desempregados, com vistas a enfrentar a grave crise social de seu paŕs (Miller, 1987, p. 16). O Panóptico pode então ser compreendido como um modelo universal de máquina discipli-

Projeto de penitenciária (1840) de N. Harou-Romain, baseado no modelo do Panóptico de Jeremy Bentham 
nar, um dispositivo fechado destinado a definir as relações de poder na vida cotidiana e a preservar as prerrogativas da lei e da ordem. "O esquema panóptico - conforme observa Foucault (1988, p. 182) - é um intensificador para qualquer aparelho de poder: assegura sua economia (em material, em pessoal, em tempo); assegura sua eficácia por seu caráter preventivo, seu funcionamento contínuo e seus mecanismos automáticos." Da mesma forma, os modernos sistemas de vigilância se difundem também e cada vez mais no corpo social, de modo a assumir uma função universalizadora; eles realizam agora, na era da eletrônica e da informática, o mesmo papel paradoxal da máquina benthamiana, ao mesmo tempo difuso e centralizador, alicerçando os mecanismos disciplinares de toda a sociedade.

Tal como o Panóptico de Bentham, os dispositivos eletrônicos de vigilância generalizam para toda a sociedade métodos de coerção nascidos no interior de presídios ou antes utilizados apenas localizadamente, na investigação ou repressão policial. Com a expansão do modelo do observatório central, a vigilância eletrônica se transforma tamberm num sistema abstrato de disciplinamento, já que, na prática, é inviável exercer uma vigilância direta sobre instituiçōes sociais, dada a magnitude estatística dos observados. Imagine-se o aparato que seria necessário para vigiar todas as conversas telefônicas de uma megalópole como São Paulo, ou para censurar todas as cartas que passam pelos seus serviços de correios. A densidade demográfica dos grandes centros urbanos não autoriza mais esquemas de controle direto, baseados no poder repressor de uma autoridade central. A própria teoria dos sistemas - disciplina que manifesta em nível teórico mais ou menos a mesma produtividade do Panoptico em nível prático - tem demonstrado que qualquer rede de distribuição não pode estar submetida a um controle centralizado assim que ultrapassa um certo nível crítico de magnitude, exigindo, em contrapartida, outras estratégias de operação, de ordem estocástica ou probabilística (Enzensberger, 1972, p. 14). Assim, a fantasia orwelliana de uma sociedade centralizada pela autoridade de um Big Brother torna-se inverossímil, largamente ultrapassada pelo modelo benthamiano de sociedade, baseado numa coerção imaginária, ficção de policiamento cultivada pela proliferação inexorável das máquinas de vigiar.

Essas máquinas, a rigor, vigiam muito pouco. Nas salas de controle, para onde afluem as imagens captadas pelos inúmeros olhos mecânicos, nunca há mais que dois ou três vigias acompanhando monotonamente o fluxo das ações cotidianas. Se eles logram flagrar uma transgressão qualquer, isso se dá mais por golpe do acaso do que por alguma pretensa infalibilidade do aparato, jâ que as máquinas de vigiar não podem funcionar senão de forma aleatória. O filme de Wim Wenders Der Americanische Freund $(O$ amigo americano, 1977) nos mostra um assassinato no metrô de Paris, captado por inúmeras câmeras de vigilância e difundido para uma quantidade ainda maior de monitores espalhados por todo o subterrâneo, sem que todavia ele fosse flagrado por qualquer vigia ou transeunte. No limite, a eficácia das redes de vigilância está menos na sua força imediata como agente repressor do que nos efeitos de homogeneidade do campo escópico que elas produzem. E preciso que vivamos permanentemente sob a suspeita de estarmos sendo vigiados, numa atmosfera de paranóia artificialmente produzida, para que a ação transgressiva possa ser coibida antes mesmo de praticada, para que o efeito de coerção seja permanente, mesmo que, na prática, a vigilância seja descontínua ou até mesmo inexistente. A sujeição real decorre, portanto, de uma relação imaginária: a vigilância torna-se função representativa de um código disciplinar, cujos designantes simbólicos são os olhos técnicos espalhados na paisagem.

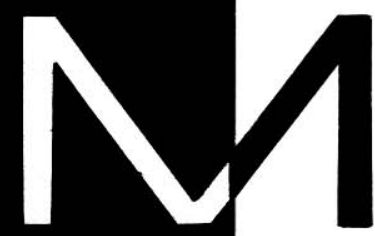

odernamente, com os progressos no campo da Inteligência Artificial, a presença do vigia tende a ser suprimida em definitivo, substituída pela prótese da percepção, a visão sintética assistida por computador. Essa "máquina de visão", como a chama Paul Virilio (1988, p. 125), permite obter algo assim como uma "visão sem olhar", a percepção de uma câmera de vigilância digitalizada por um computador capaz de analisar os dados óticos colhidos, confrontá-los com um padrão de referências e interpretar automaticamente o que ocorre dentro do campo visual. Com a automação da percepção - a "visiônica", como já se convencionou chamar essa área da tecnologia - estamos delegando inteiramente à máquina a função disciplinar e, por conseqüência, despersonalizando em definitivo o exercício do poder. Todo o sistema hierárquico que ainda organiza certas estruturas de poder em nossa sociedade poderá tornar-se obsoleto em pouco tempo, cabendo à percepção sintética e aos experts systems o controle automático de atividades tão diferenciadas como a produção industrial, o tra- 


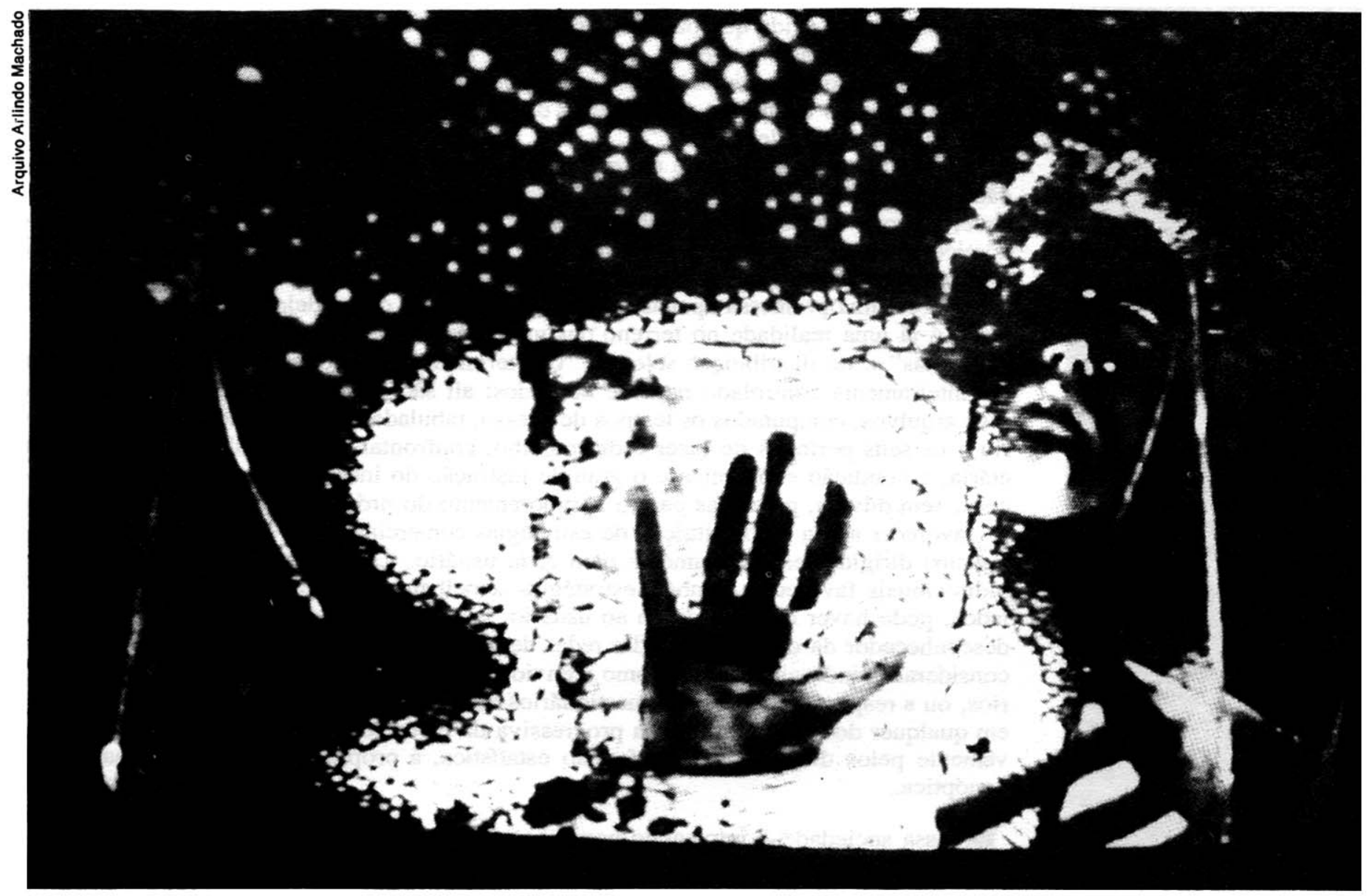

balho nos escritórios e o lazer em espaços públicos. A visiônica já é hoje praticada em nível militar, por exemplo em pontos estratégicos das fronteiras e costas de alguns paŕses. O Panóptico atinge assim o seu ponto máximo de eficiência, na medida mesma em que se reduz a uma fórmula inteiramente abstrata, quase uma equação matemática, na medida ainda em que, livre da falibilidade humana, pōe-se a constranger os homens com a logica implacável de seu mecanismo técnico.

\section{O VIDENTE E O VISfVEL}

Já houve quem fizesse (Mellencamp, 1986, pp. 197-204; James, 1986, p. 88; Sodré, 1984, p. 24s) uma aproximação conceitual entre o sistema eletrônico de vigilância e a estrutura de funcionamento da televisão. Ora por causa do uso comum de câmeras e monitores da mesma natureza, ora devido à semelhança entre o regime broadcasting de difusão e a estrutura em teia de aranha do dispositivo panóptico de vigilância, outras vezes ainda pelo fato de, na televisão, os apresentadores se endereçarem diretamente à câmera, dando aos espectadores a impressão de estarem sendo senão vigiados, pelo menos interpelados por um olhar. A comparação é, na maioria dos casos, apenas metafórica, mas não deixa de apontar para alguma coisa mais funda, menos evidente e mais diffcil de formular. Virilio (1988, p. 136) nos sugere que há algo de muito significante no fato dos aparelhos receptores de televisão serem agora instalados nas celas dos prisioneiros em unidades individuais e não mais, como ocorria antes, em salas públicas destinadas a um coletivo. $\mathrm{E}$ tambêm no fato das medidas de audiência televisual serem agora realizadas por um aparelho instalado dentro do próprio televisor e conectado com a central de estatísticas através de cabo telefônico. Esse aparelho não apenas registra o canal sintonizado e o tempo de sintonia, mas também, através de sensores fotelétricos, se o telespectador está de fato presente diante da tela, se ele não se ausentou apesar do aparelho ligado. A tática dá às redes de emissão e aos seus patrocinadores alguma garantia de controle sobre os efeitos dispersivos do zapping televisual, mas prefigura tam-

rantia de controle sobre os efeitos dispersivos do zapping televisual, mas prefigura tam- 
bêm o rascunho, ainda que bastante primário, de um olho fotelétrico de vigilância. Primário, mas destinado a evoluir e não é difícil de imaginar, dentro de algum tempo, a generalização do procedimento, com os dispositivos de registro de audiência já incorporados a todos os aparelhos de recepção e conectados à central pela mesma via eletromagnética do sinal televisual.

Certamente, não se trata de um complô maquiavélico destinado a constranger o cidadão, como em certas ficções pseudocientíficas. Um novo dispositivo panóptico permanece, como o antigo, dirigido no sentido de uma otimização dos sistemas legal e econômico: trata-se de extrair a produtividade máxima das redes eletrônicas de difusão já implantadas profundamente na vida social. Nesse sentido, aquilo que, por enquanto, permanece uma promessa apenas hipotética no âmbito do modelo broadcasting de televisão é já uma realidade no terreno das modalidades narroncasting (televisões "especializadas" e de distribuição seletiva). Um terminal de vídeo-texto, por exemplo, pode ser inteiramente controlado na base de dados: ali são registrados todos os acessos aos seus arquivos, computados os tempos de acesso, tabuladas as preferências de cada usuário e os seus períodos de lazer e de trabalho, confrontando os resultados com a faixa etária, a condição econômica e o grau de instrução do indivíduo em questão. Informações, sem dúvida, preciosas para o aprimoramento do próprio sistema de difusão, além de favorecer ainda a constituição de estratégias comerciais (mas às vezes também ideológicas) dirigidas especificamente para cada usuário. Certos regimes de TV a cabo ou bidirecionais favorecem também estratégias semelhantes. É verdade que, em casos isolados, pode haver coerção direta ao usuário, sobretudo quando este, inadvertidamente, desconhecedor da centralização das redes de dados, utiliza seu terminal para finalidades consideradas indesejáveis, tais como o envio de mensagens pornográficas a outros usuários, ou a resposta indelicada a questionários dos programas. O que salta à vista, porém, em qualquer dos casos, é a perda progressiva da privacidade do cidadão, invadida suavemente pelos dispositivos de aferição estatística, a própria essência da formalização panoptica.

ossa sociedade - retomando novamente Foucault - é menos a dos espetáculos do que a da vigilância. Mas a sua sabedoria está em transformar o próprio espetáculo em observatório de vigilância. "A partir do momento em que os telespectadores ligam seus receptores, são eles mesmos, prisioneiros ou não, que entram no campo da televisão, um campo sobre o qual eles não têm qualquer poder de intervenção" (Virilio, 1988, p. 136). Mas a recíproca também é verdadeira: em nossa sociedade marcada pelo destino do Panóptico, a própria vigilância resulta também em espetáculo. As telas dos monitores de vigilância, por exemplo, não são mais objetos secretos, reservados apenas às salas de controle e observação. Antes, elas se esparramam pela paisagem vigiada, oferecendo-se como espetáculo aos seus próprios protagonistas, para que o olho público assuma ele mesmo a tarefa da vigilância. Ademais, é de se notar a maneira como a própria televisão consegue transformar em atração situações típicas de vigilância. $\mathrm{O}$ exemplo clássico é Candid camera, programa animado por Allen Funt e levado ao ar pela primeira vez na televisão americana em 1948. Nele, "pessoas comuns" eram filmadas por câmeras ocultas em situações ridículas ou humorísticas provocadas pela própria equipe de produção. Colocado na situação de voyeurismo explícito, o público americano se divertiu durante várias décadas com o vexame alheio. No Brasil, Ślvio Santos utilizou procedimentos de câmera cândida em seu programa dominical, mas já inseridos numa situação controlada de gincana eletrônica. Um exemplo mais radical poderia ser a série An american family, exibida pela primeira vez na televisão americana em 1972 e que deu nascimento àquilo que Jean Baudrillard chama de $T V$-vérité: a vida cotidiana de uma famflia americana (uma famflia de verdade, não se trata de atores, nem de ficção) observada minuciosamente em sua privacidade por inúmeras câmeras de televisão, durante sete meses seguidos. $\mathrm{O}$ polêmico seriado mostrou menos o que $\epsilon$, de um ponto de vista documental, uma típica famflia americana, do que o que acontece quando um grupo de pessoas é submetido sistematicamente, ininterruptamente, até mesmo na sua intimidade mais secreta, ao olhar voyeurista de câmeras eletrônicas que o colocam em conexão com vinte milhões de peeping toms espalhados por todo um país. Com a generalização da técnica para programas de outra natureza, o telejornalismo acabou por se revelar o "gênero" por excelência da câmera cândida, a ponto de seus achados de espionagem e bisbilhotice serem saudados como "furos" de reportagens. $\mathrm{O}$ assim chamado jornalismo investigativo, aliás, se confunde cada vez mais com a inves- 
tigaçăo policial propriamente dita, a ponto de realizar, muitas vezes, o sonho benthamiano de uma sociedade autovigiada.

Circuitos fechados de televisão são hoje largamente utilizados em motéis como recursos de estimulação erótica: os amantes se colocam no campo de visão da câmera e, enquanto se acariciam, contemplam-se na tela do monitor, esperando pela intensificação do estímulo sexual. Há casais que já não conseguem mais sentir atração sexual se não puderem contemplar-se, ao mesmo tempo, numa tela de TV. As cenas de estimulação eletrônica são evidentemente privadas, mas já se conhece muito bem as formas como elas são contrabandeadas pelos motéis. Em alguns casos, o circuito fechado se converte em verdadeiro sistema de vigilância, através do qual a administração do motel controla o que se passa dentro de cada quarto. Em outros, as cenas dos amantes são gravadas através de cabos ocultos e utilizadas no próprio estabelecimento para a estimulação de outros amantes, após terem sido digitalizadas as faces dos primeiros para esconder suas identidades. O mais surpreendente é que, às vezes, os amantes sabem disso e nem por isso se inibem diante das câmeras; até pelo contrário, a eventualidade de estar sendo vigiados dá um sabor de emoção à aventura. $\mathrm{O}$ que há de paradoxal nesse exemplo é que ele torna evidente a facilidade com que se pode, diante da imagem eletrônica, passar da condição de observador a observado, ou de espectador a espetáculo, dada a reversibilidade das tecnologias de registro e exibição. $\mathrm{Na}$ vitrine de uma loja de artigos eletrônicos, contemplo os aparelhos receptores de TV, que me dão a programação das redes, mas contemplo-me também a mim mesmo nos monitores dos circuitos de vigilância, que se misturam àqueles e com eles se confundem. A linha de separação entre o vigia e o vigiado é tão tênue quanto aquela que separava, no Panóptico de Bentham, a sentinela dos enclausurados, de um lado, e dos visitantes, de outro.

No começo do século, Freud (1972, pp. 1144) já previa a reversão da pulsão do olhar no seu oposto (a pulsão de sentir-se olhado). Isso significava, na linguagem das perversões, que voyeurismo e exibicionismo eram duas faces de uma mesma moeda: olhar não era outra coisa que mirar-se no espelho do olho do outro. Posteriormente, Merleau-Ponty e Lacan, para ficar apenas nos nomes mais marcantes, retomaram o tema freudiano da reversibilidade do olhar entre os polos vidente e visfvel. O mesmo campo escópico que contitui o sujeito - ex-
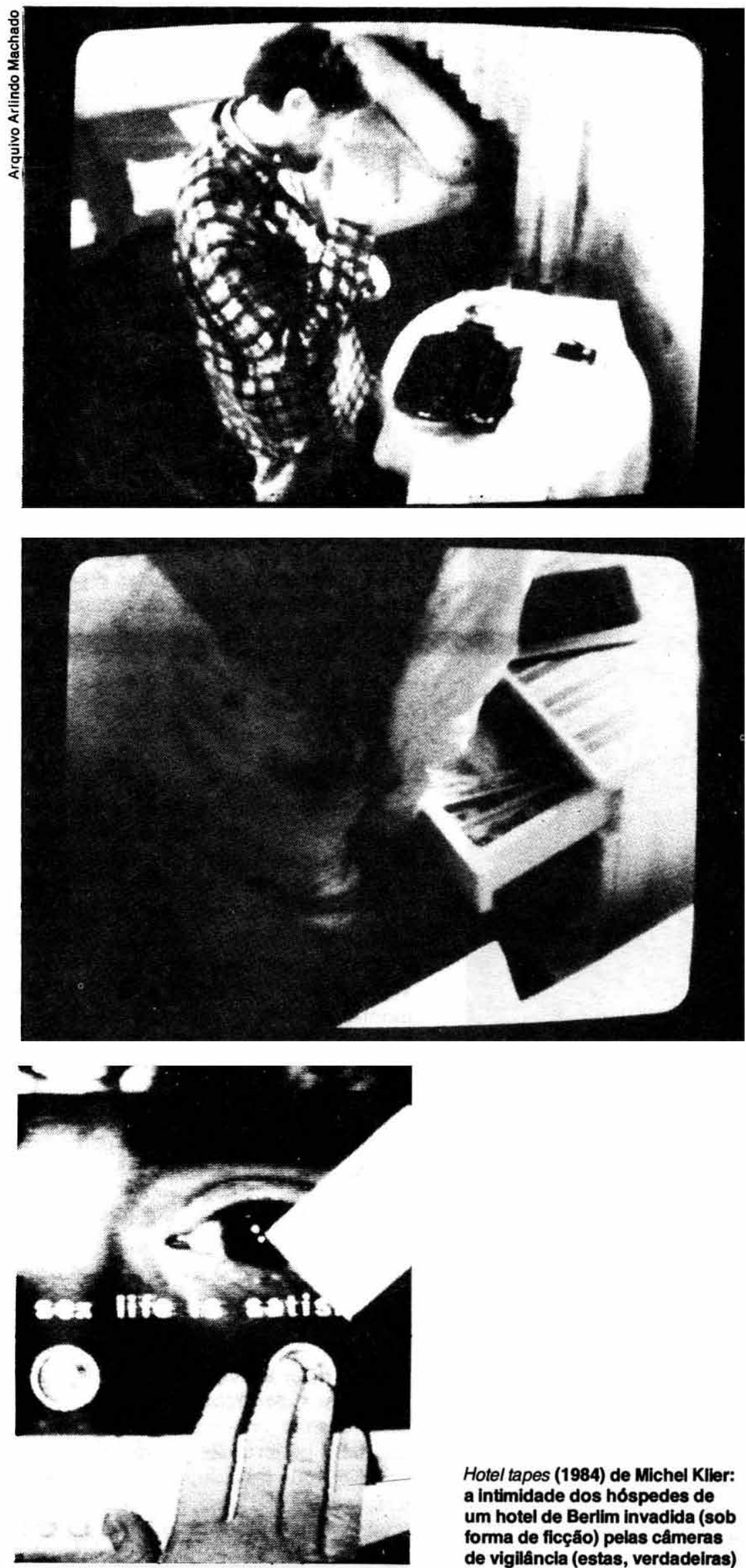

Hotel tapes (1984) de Michel Kller: a intimidade dos hóspedes de um hotel de Berlim invadida (sob forma de ficçáo) pelas câmeras de vigilância (estas, verdadeiras)

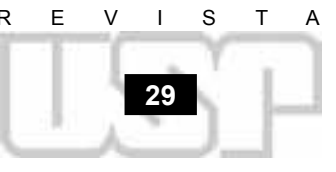


plicaram eles - é também o local onde o sujeito fracassa como fonte originária, como foco, como "ponto de vista", pois não é o olhar senão um "quiasma", ponto de cruzamento e de reversibilidade do eu e do outro, dupla inscrição do dentro e do fora (Merleau-Ponty, 1971, pp. 235-7; Lacan, 1985, pp. 90-115). Toda essa conceituação, entretanto, que no discurso abstrato da filosofia e da psicanálise aparece como esforço de retórica ou jogo de expressão, resulta claramente colocada em evidência nas máquinas de vigiar e concretizada na ambigüidade ocular do Panóptico universal. A multiplicação das câmeras de vigilância na paisagem social põe a nu esse desdobramento do ponto de vista, não sendo mais de ninguém o olho do outro, mas apenas uma virtualidade escópica que pode ser ocupada por qualquer um. Agora, com a protese ocular, com o olho sintético e infográfico da máquina, não é mais uma figura de linguagem dizer, como os psicanalistas, que as pedras nos vêem. Os olhos estão não apenas fora de nós, mas também fora do vivente como especie. "Por detrás do muro, jâ não vejo mais o cartaz; diante do muro, o cartaz se impõe a mim, sua imagem me percebe." Não ć Lacan quem fala; ê Virilio (1988, p. 131).

\section{O GIGANTE}

O último filme de Fritz Lang - Die Tausend Augen des Dr. Mabuse (Os mil olhos do Dr. Mabuse, 1960) foi constrúfo inteiramente em cima da idéia da onipresença das máquinas de vigiar. Acredita-se que a concepção do filme nasceu de uma informação, veiculada na epoca de sua realização, de que os nazistas haviam planejado construir um hotel, destinado a diplomatas e personalidades políticas, cujos quartos estariam dotados de microfones ocultos, antecipando em cerca de trinta anos o episódio de Watergate. $O$ novo Mabuse adquiriu um hotel inacabado ao término da guerra e finalizou sua construção, equipando-o com câmeras de vigilância dissimuladas. Assim, colocado na sala de controle do hotel, Mabuse acompanha tudo o que se passa nos quartos, através das imagens e dos sons exibidos nos monitores. Desse local, ele executa uma verdadeira miseen-scène, transformando os hóspedes em personagens de uma trama policial que ele próprio arquitetou. Sem o saber e dirigidas secretamente pelo astucioso bandido, as personalidades do hotel cumprem os planos de Mabuse até as últimas conseqüências, transformando-se inadvertidamente em seus cúmplices.

O circuito de vigilância de Mabuse, entretanto, resulta imperfeito como dispositivo panóptico. Pois se há algo que marca a essência mesma da vigilância eletrônica é que nela nenhum vidente está mais implicado. As câmeras de vigilância não dependem, para funcionar, de um operador centralizado, muito menos de um gênio da manipulação que, da sua sala de controle, rege o destino dos observados como peças de um tabuleiro de xadrez. É bem mais provável que não haja mais ninguém olhando para os monitores de vigilância, a não ser os próprios transeuntes, a título de distração. Ou que os próprios monitores já estejam sendo substiturdos por olhos sintéticos regidos por um programa. Sempre dissemos, a propósito da fotografia, do cinema e mesmo da televisão, que não há câmera sem que um olho humano esteja implicado nela, donde o tema romântico do artista atrás da máquina. Os circuitos de vigilância, entretanto, parecem dispostos a dispensar inteiramente o homem que fica atrás da câmera. Tudo neles se automatiza e caminha na direção da prótese perceptiva. Neles não há mais lugar para um mestre regente, nem mesmo para um Dr. Mabuse.

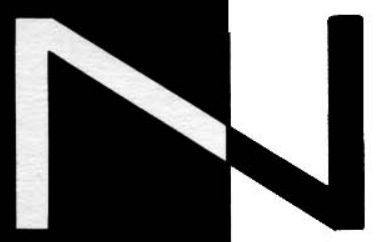

a contramão dos tempos, Michel Klier decide realizar uma obra que é o último traço da subjetividade visual, o "canto do cisne" definitivo do artista atrás da câmera, mas também e paradoxalmente o primeiro exemplar de uma arte da protese perceptiva, "o ponto de mutação do avanço inexorável das tecnologias da representação, de sua instrumentalização militar, científica e policial ao longo dos séculos" (Virilio, 1988, p. 104). Tal como Mabuse, mas não mais em nível da fábula e da ficção. Klier senta-se diante dos monitores das salas de controle dos aeroportos, supermercados e serviços de trânsito, coloca sob sua direção os dipositivos de controle remoto das câmeras e põe-se a reger, não uma trama maquiavélica como a de Lang, mas o que bem poderia ser o espetáculo de uma dramaturgia crepuscular deste final de milênio. Estamos falando, e claro, de Der Riese.

Tarefa difícil, quase impossível, pois a máquina resiste a uma abordagem qualitativa, teima em exibir sua natureza mecânica e não oferece elementos para qualquer atribuição desviante de sua finalidade exclusiva de vigilância. Os percursos das câmeras forte- 
mente marcados, rigidamente estabelecidos, sempre em linha reta e na posição das coordenadas cartesianas (para cima ou para baixo, para a direita ou para a esquerda) não lembram em nada os travelings suaves do cinema, favorecidos pelos tripes de cabeça fluida, ou as suas panorâmicas ăgeis e elegantes. Antes, aqui os movimentos são imotivados, o olhar é errático e arbitrário, em geral governado apenas pelas surpresas do acaso. Não havendo intenção significante, o olho mecânico não transmite, a princípio, qualquer informação. Ele se contenta apenas em ficar permanentemente funcionando, registrando em tempo real a banalidade de um cotidiano anódino. "O mais assombroso nessa fita e, sem dúvida, a insignificância, a vacuidade desse olhar cego. Trata-se aqui de um pensamento ou de um olhar vazio, puramente tecnologico" (Mèredieu, 1988, p. 17). Nenhum sentido, talvez apenas um, secundário, imotivado, resultado de uma associação semântica: na tela dos monitores de vigilância, todos parecem suspeitos; até mesmo o mais vulgar dos homens, como nos romances de Kafka, parece acometido de culpa; os cenários lembram insistentemente a paisagem de um crime que está prestes a ser cometido. Tudo miragem, pois na verdade nada acontece, nada pode acontecer.

Porém, na sala de controle, diante das telas eletrônicas e dos botões de monitoramento, Klier força o sentido: segue longamente o percurso de uma simples pomba na calçada à procura de comida; instaura um esboço de ficção, fazendo simular um assalto num supermercado; edita "em continuidade" o percurso dos transportadores de valores, parodiando um efeito cinematográfico; detém o fluxo das pessoas nas ruas, fazendo-as caminhar em câmera lenta ou congelando-as num único frame. E quando tudo isso ainda não lhe parece suficiente, salta para o contracampo do dispositivo de segurança, tornando visíveis as câmeras ocultas e os monitores das salas de controle. Numa das seqüências mais amargas do vídeo, ele sentase diante de uma máquina de retrato falado e se põe a construir rostos artificiais, rostos que, pelo fato mesmo de desfilarem num banco de imagens fisionômicas da polícia, sugerem uma multidão de deserdados anônimos, criminosos, psicopatas, assassinados e atropelados que talvez nunca existiram, mas que poderiam ter existido ou vir ainda a existir. Metade reais e metade imaginários, esses rostos sintéticos se parecem estreitamente com aqueles que desfilam ininterruptamente nas telas dos monitores de vigilância. Mas eles são, paradoxalmente,
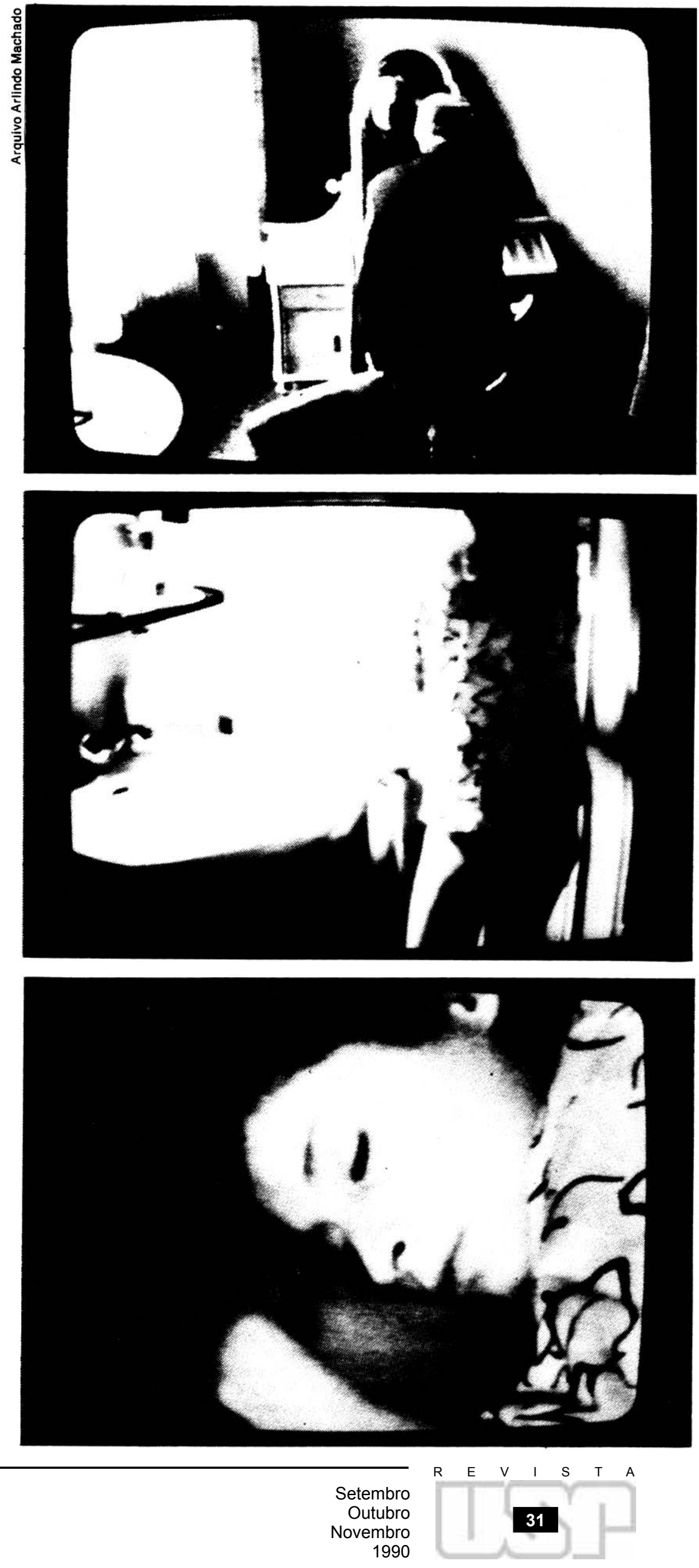


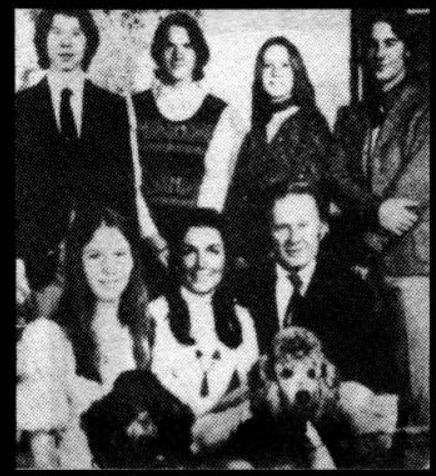

A familia Loud, de Santa Bárbara, Califórnia, antes de ser destroçada pelas câmeras voyeuristas de An american family. (1972-73), seriado produzido pela rede estatal americana PBS. A frente, o casal Bill e Pat Loud, que se divorciou durantes as filmagens: atrás e à direita, Lance Loud, flagrado em sua homossexualidade pelas câmeras as únicas faces "humanas" vistas em close-up no vídeo (a seqüência do monitoramento da sessão de psiquiatria é mostrada em plano americano), o que não deixa de ser uma inversão de valores bastante significativa.

Há alguns momentos, entretanto, de pura transcendência, em que as imagens saltam para fora de sua couraça disciplinar. Esses momentos são possibilitados pelo único elemento estranho dentro do campo da vigilância, algo que está inapelavelmente fora do quadro, num espaço off inassimilável ao dispositivo panóptico: a música acrescentada às imagens. A trilha sonora de Der Riese combina som direto, captado pelas próprias câmeras de vigilância, com uma seleção musical criteriosa e significante. Essa trilha sonora, ao mesmo tempo em que sugere o lado dramático de um mundo enclausurado, introjeta também emoção nessas paisagens descarnadas, invertendo a linha de força das imagens. Tais momentos de intensidade expressiva, nós os encontramos particularmente na seqüência dos rostos sintéticos, ou da gravação do traçado encefalogramático, ou ainda da estação de veraneio, onde até mesmo o ato inocente de tomar sol à beira-mar é dissecado por poderosos aparatos de vigilância. "Dramática, pesada, perturbada, impregnante, repleta de intenção, sacudida por súbitas quedas e pausas, a trilha sonora de $D e r$ Riese - verdadeiro arquétipo do que se entende por música de filme - redobra longinquamente o circuito fechado das imagens, mas força também a sua abertura, como decorrência de suas secreções - um feixe de ondas, carregado de certezas e incertezas, prováveis índices e falsas pistas, cadeias forçadas de eventos, conhecimentos assumidos, segredos ameaçados - sementes de ficção que aspiram o interior, tensões centrais em direção às margens. A música joga o centro para fora" (Fargier, 1984, p. 44).

Surpreendente é ver nascer uma nova geração de artistas capaz de redescobrir a vida num mundo centralizado pelas máquinas, num mundo que toma para si o destino do $\mathrm{Pa}-$ nóptico. Um modesto filme do armênio Atom Egoyan, Family viewing (1987), demonstrou recentemente que a proliferação de máquinas à nossa volta, a sua penetração dentro de nossas próprias casas e até mesmo na nossa vida mais íntima estão criando outras relações humanas e até mesmo dando expressão a emoções novas, nunca antes experimentadas. Em escala um pouco mais reduzida, encontramos essa constatação também no Paris/Texas (1984) de Wim Wenders, notadamente na figura do menino para quem a comunicação passa necessariamente pelo walkie-talkie e do casal que redescobre o diálogo através dos intercomunicadores do peep show. Na perspectiva inversa, sob um enfoque moralista e conservador, a mesma constatação está também abertamente colocada no sex, lies and videotape (1989) de Steven Soderbergh. Klier faz parte dessa geração emergente de poetas capaz de transformar em exercícios de sensibilidade e paixão (mas também em conhecimento crítico) as novas e intrincadas relações subjetivas e objetivas colocadas pelas sociedades industriais avançadas. Ao invés de apropriar-se das imagens de vigilância apenas como pretexto para uma interpretação semântica distanciada, ele esforça-se para torná-las sensíveis em toda sua intensidade, em toda sua extensão, em todas as suas contradições, de modo que possamos estar mais maduros para viver, entender e superar o nosso tempo.

\section{BIBLIOGRAFIA}

BENTHAM, Jeremy. Oeuvres, vol. 1. Bruxelles, Louis Hauman, 1829.

BROOKS, Rosetta. "Seeing with our ears: music for TV", in The arts for television (Kathy Rae Huffman, Dorine Mignot, ed.). Los Angeles/Amsterdam, The Museum of Contemporay Art/Stedelijk Museum, 1987. ENZENSBERGER, Hans Magnus. Elementos para una teorfa de los medios de comunicacion. Barcelona, Anagrama, 1972.

FARGIER, Jean-Paul. "The hidden side of the moon", in Het lumineuze beeld/ The luminous image (Dorine Mignot, ed.). Amsterdam, Stedelijk Museum, 1984.

FOUCAULT, Michel. Vigiar e punir: história da violência nas prisōes. Petrópolis, Vozes, 1988.

FREUD, Sigmund. “Pulsions et destins des pulsions", in Métapsychologie. Paris, Gallimard, 1972.

GLATZER, Hal. The birds of Babel. Indianopolis, Howard W. Sams, 1983.

JAMES, David. "Intervention: the contexts of negation for video and its criticism", in Resolution: a critique of video art (Patti Podesta, ed.). Los Angeles, LACE, 1986.

KRAMER, Brigitte e KLIER Michel. "Der Riese", in Surveillance (Branda Miller, Deborah Irmas, ed.). Los Angeles, LACE, 1987.

LACAN, Jacques. O seminário. Livro 11: os quatro conceitos fundamentais da psicanálise. Rio de Janeiro, Jorge Zahar, 1985.

MELLENCAMP, Patricia. “Avant-garde TV: simulation and surveillance”, in Vidéo (René Payant, ed.). Montréal, Artexte, 1986.

MĖREDIEU, Florence de. "Le crustacé et la prothèse", in Paysages virtuels, Paris, Dis Voir, 1988.

MERLEAU-PONTY, Maurice. $O$ vistvel e o invistvel. São Paulo, Perspectiva, 1971.

MILLER, Jacques-Alain. "Jeremy Bentham's panoptic device", in October. Cambridge, 41, summer, 1987.

SODRÉ, Muniz. A máquina de Narciso. Rio de Janeiro, Achiamé, 1984.

VIRILIO, Paul. La machine de vision. Paris, Galilee, 1988. 